


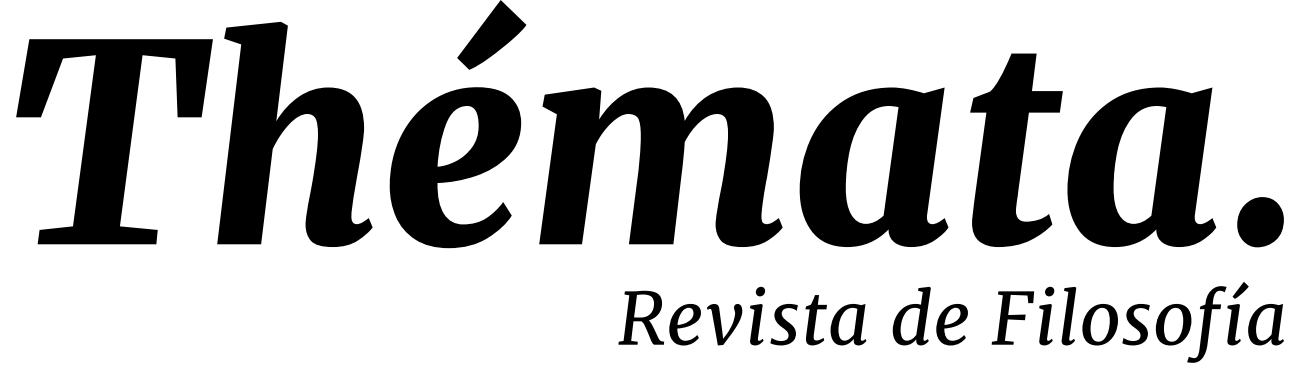

\section{La transmisión filosófica. Pensamiento de Javier Hernández-Pacheco Sanz}

Alejandro Martín Navarro (Coord.)

ESPECIAL THÉMATA

2022

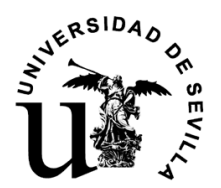

ISSN 0212-8365

e-ISSN 2253-900X

DOI: $10.12795 /$ themata

revistascientificas.us.es/index.php/themata

https://editorial.us.es/es/revistas/themata-revista-de-filosofia 
Thémata. Revista de Filosofía.

Número Extra

Thémata. Revista de Filosofía nace en el año 1983 con la intención de proporcionar a quienes investigan y producen en filosofía un cauce para publicar sus trabajos y fomentar un diálogo abierto sin condicionamientos ideológicos. En sus inicios participaron en el proyecto las Universidades de Murcia, Málaga y Sevilla, pero pronto quedaron como gestores de la revista un grupo de docentes de la Facultad de Filosofía de la Universidad de Sevilla.

Una preocupación constante de sus realizadores ha sido fomentar los planteamientos interdisciplinares. La revista ha estado abierta siempre a colaboradores de todas las latitudes y ha cubierto toda la gama del espectro filosófico, de lo que constituye una buena prueba la extensa nómina de autores que han publicado en sus páginas. En sus páginas pueden encontrarse trabajos de todas las disciplinas filosóficas: Historia de la Filosofía, Metafísica, Gnoseología, Epistemología, Lógica, Ética, Estética, Filosofía Política, Filosofía del Lenguaje, Filosofía de la Mente, Filosofía de la Ciencia, Filosofía de la Historia, Filosofía de la Cultura, etc. También ha querido ser muy flexible a la hora de acoger nuevos proyectos, fomentar discusiones sobre temas controvertidos y abrirse a nuevos valores filosóficos. Por esta razón, los investigadores jóvenes siempre han encontrado bien abiertas las puertas de la revista.

\section{Equipo editorial / Editorial Team Bases de Datos y Repertorios}

Director honorario

Jacinto Choza Armenta

jchoza@us.es

Director

Fernando Infante del Rosal

finfante@us.es

Director Adjunto

José Manuel Sánchez López

themata@us.es

Subdirectores

Jesús Navarro Reyes

jnr@us.es

Inmaculada Murcia Serrano

imurcia@us.es

Jesús de Garay

jgaray@us.es

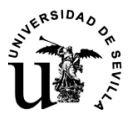

Facultad de Filosofía. Universidad de Sevilla

Departamento de Estética e Historia de la

Filosofía

Departamento de Filosofía y Lógica y Filosofía

de la Ciencia

Departamento de Metafísica y Corrientes

Actuales de la Filosofía, Ética y Filosofía Política

Camilo José Cela s/n, 41018 Sevilla (España)

e-mail: themata@us.es
Bibliográficas internacionales

Emerging Sources Citation Index (Web of

Science Group-Clarivate Analytics)

Dialnet (España)

Francis, Philosophie. INIST-CNRS (France)

Philosopher's Index (Bowling Green, OH, USA)

Directory of Open Access Journals (DOAJ)

Repertoire Bibliographique de Philosophie

(Louvain, Belgique)

Ulrich's Internacional Periodicals Directory

(New York, USA)

DialogJournalNameFinder (Palo Alto, CA, USA)

Periodicals Index Online (Michigan, USA)

Index Copernicus World of Journals

Gale-Cengage Learning-Informe Académico

Academic Journal Database

DULCINEA

Google Scholar

Electra

Bulletin signaletique. Philosophie, CNRS

(France)

Bibliográficas nacionales

ISOC - Filosofía. CINDOC (España)

De evaluación de la calidad de revistas

CARHUS Plus

ERIH PLUS Philosophy (2016)

REDIB

Latindex 2.0

MIAR

CIRC

DICE

Política editorial y directrices para autores/as, al final de la revista.

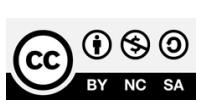


Thémata. Revista de Filosofía.

\section{Consejo Editor / Editorial Board}

\section{ARGENTINA}

Flavia Dezzuto, Universidad Nacional de Córdoba

ALEMANIA

Alberto Ciria, Munich

\section{CANADÁ}

Óscar Moro, University of New Found Land

CHILE

Mariano De la Maza, Universidad Católica de Chile

José Santos Herceg, Universidad de Santiago de Chile

\section{COLOMBIA}

Martha Cecilia Betancur García, Universidad de Caldas

Víctor Hugo Gómez Yepes, Universidad Pontificia Bolivariana

Gustavo Adolfo Muñoz Marín, Universidad Pontificia Bolivariana

\section{ESPAÑA}

Alfonso García Marqués, Universidad de Murcia

Antonio De Diego González, Universidad de Sevilla

Avelina Cecilia Lafuente, Universidad de Sevilla

Carlos Ortiz Landázuri, Universidad de Navarra

Celso Sánchez Capdequí, Universidad Pública de Navarra

Elena Ronzón Fernández, Universidad de Oviedo

Enrique Anrubia, Universidad CEU Cardenal Herrera

Federico Basáñez, Universidad de Sevilla

Fernando Wulff, Universidad de Málaga

Fernando M. Pérez Herranz, Universidad de Alicante

Fernando Pérez-Borbujo, Universitat Pompeu Fabra

Francisco Rodríguez Valls, Universidad de Sevilla

Ildefonso Murillo, Universidad Pontificia de Salamanca

Irene Comins Mingol, Universitat Jaume I Jacinto Rivera de Rosales Chacón, † UNED Joan B. Llinares, Universitat de València Jorge Ayala, Universidad de Zaragoza José Manuel Chillón Lorenzo, Universidad de Valladolid
Juan García González, Universidad de Málaga

Juan José Padial Benticuaga, Universidad de Málaga

Luis Miguel Arroyo Arrayás, Universidad de Huelva

Ma Luz Pintos Peñaranda, Universidad de Santiago de Compostela

Marcelo López Cambronero, Instituto de Filosofía Edith Stein

María del Carmen Paredes, Universidad de Salamanca

Octavi Piulats Riu, Universitat de Barcelona

Óscar Barroso Fernández, Universidad de Granada

Pedro Jesús Teruel, Universitat de València

Ramón Román Alcalá, Universidad de Córdoba

Ricardo Parellada, Universidad Complutense de Madrid

Sonia París Albert, Universitat Jaume I

Tomás Domingo Moratalla, UNED

\section{ESTADOS UNIDOS}

Witold Wolny, University of Virginia)

Thao Theresa Phuong Phan, University of Maryland

\section{REINO UNIDO}

Beatriz Caballero Rodríguez, University of Strathclyde

ITALIA

Luigi Bonanate, Università di Torino

\section{MÉXICO}

Rafael De Gasperín, Instituto Tecnológico de Monterrey

Julio Quesada, Universidad Veracruzana

Adriana Rodríguez Barraza, Universidad Veracruzana

PERÚ

Ananí Gutiérrez Aguilar, Universidad Nacional de San Agustín de Arequipa y Universidad Católica de Santa María

Nicanor Wong Ortiz, Universidad San Ignacio de Loyola

\section{PORTUGAL}

Yolanda Espiña, Universidade Católica Portuguesa

\section{TURQUÍA}

Mehmet Özkan, SETA Foundation for Political, Economic and Social Research 
Thémata. Revista de Filosofía.

\section{Comité Científico Asesor / Advisory Board}

ARGENTINA

Graciela Maturo, Universidad de Buenos Aires - CONICET

Jaime Peire, Universidad Nacional de Tres de Febrero- CONICET

\section{ALEMANIA}

Tomás Gil, Freie Universität Berlin

Fernando Inciarte, $\dagger$ Westfälische WilhelmsUniversität

Otto Saame, † Universität Mainz

\section{BULGARIA}

Lazar Koprinarov, South-West University 'Neofit Rilski'

CHILE

Carla Corduá, Universidad de Chile

Roberto Torreti, Universidad de Chile

COLOMBIA

Carlos Másmela, Universidad de Antioquía Fernando Zalamea, Universidad Nacional de Colombia

\section{ESPAÑA}

Agustín González Gallego, Universitat de Barcelona

Alejandro Llano, Universidad de Navarra Andrés Ortiz-Osés, Universidad de Deusto Ángel D'ors, † Universidad Complutense de Madrid

Antonio Hermosa Andújar, Universidad de Sevilla

Carlos Beorlegui Rodríguez, Universidad de Deusto

Concha Roldán Panadero, Instituto de Filosofía, CCHS-CSIC

Daniel Innerarity Grau, Ikerbasque, Basque Foundation for Science

Francisco Soler, Universidad de Sevilla Ignacio Falgueras, Universidad de Málaga Javier San Martín, UNED

Jesús Arellano Catalán, † Universidad de Sevilla

Joaquín Lomba Fuentes, Universidad de Zaragoza

Jorge Vicente Arregui, † Universidad de Málaga José María Prieto Soler, † Universidad de Sevilla José Rubio, Universidad de Málaga Juan Antonio Estrada Díaz, Universidad de Granada

Juan Arana Cañedo-Argüelles, Universidad de Sevilla
Luis Girón, Universidad Complutense de Madrid

Manuel Fontán Del Junco, Fundación March

Manuel Jiménez Redondo, Universitat de València

Marcelino Rodríguez Donís, Universidad de Sevilla

Miguel García-Baró López, Universidad Pontificia Comillas

Modesto Berciano, Universidad de Oviedo

Pascual Martínez-Freire, Universidad de Málaga

Rafael Alvira, Universidad de Navarra

Teresa Bejarano Fernández, Universidad de Sevilla

Vicente San Félix Vidarte, Universitat de València

\section{ESTADOS UNIDOS}

Lawrence Cahoone, University of Boston

FRANCIA

Nicolás Grimaldi, Université Paris IV-Sorbonne

\section{PARAGUAY}

Mario Ramos Reyes, Universidad Católica de Asunción

\section{REINO UNIDO}

Alexander Broadie, University of Glasgow

ISRAEL

Marcelo Dascal, † Tel Aviv University

ITALIA

Massimo Campanini, Università di Napoli l'Orientale

Maurizio Pagano, Università degli Studi del Piamonte Orientale. Amedeo Avogadro

JAPóN

Juan Masiá, Sophia University, Tokio

\section{MÉXICO}

Jaime Méndez Jiménez, Universidad Veracruzana

Ana Laura Santamaría, Instituto Tecnológico de Monterrey

Héctor Zagal, Universidad Panamericana

VENEZUELA

Seny Hernández Ledezma, Universidad Central de Venezuela

Thémata. Revista de Filosofía agradece la labor realizada desde su inicio por sus anteriores directores: Jacinto Choza, Juan Arana y Jesús de Garay. 


\section{Índice.}

\section{LA TRANSMISIÓN FILOSÓFICA. PENSAMIENTO DE JAVIER HERNÁNDEZ-}

PACHECO SANZ_ESPECIAL THÉMATA

9 El acto filosófico. En recuerdo de Javier Hernández-Pacheco Sanz Fernando Infante del Rosal

14 Presentación

Alejandro Martín Navarro (Coord.)

SEMBLANZAS Y RECUERDOS_JAVIER HERNÁNDEZ-PACHECO SANZ,

TRANSMISIÓN Y ENSEÑANZA DE LA FILOSOFÍA

19 Treinta y siete años con Pacheco. Variaciones sobre el cristianismo Jacinto Choza Armenta

$51 \quad$ Historia de un hombre sabio y bueno Juan Arana Cañedo-Argüelles

$54 \quad$ Una fuerza de la naturaleza José Manuel Sánchez López

58 In Memoriam a Javier Hernández-Pacheco Urbano Ferrer Santos

65 Recordando al profesor Javier Hernández-Pacheco Esperanza María Domínguez Sabido

OBRA Y PENSAMIENTO DE JAVIER HERNÁNDEZ-PACHECO SANZ_ARTÍCULOS

$71 \quad$ Una conversación pendiente Jesús de Garay Suárez-Llanos

87 Un viaje de ida y vuelta: de cómo el refugio se torna apertura. El proyectar(se) como apertura a lo Otro Elisa Fernández Bascones

107 Max Horkheimer y el anhelo de lo completamente Otro. (A propósito de la interpretación de la filosofía de Max Horkheimer de Javier Hernández-Pacheco) José Manuel Panea Márquez 
Thémata. Revista de Filosofía.

124 Javier Hernández-Pacheco: fe y filosofía

Lidia Romero Sánchez

$141 \quad$ La plenitud hacia la que tendemos: historia de una discusión truncada.

Francisco José Soler Gil

161 Tábula gratulatoria.

163 Política editorial.

166 Directrices para autores/as.

ILUSTRACIÓN DE CUBIERTA: Javier Infante 
Thémata. Revista de Filosofía.
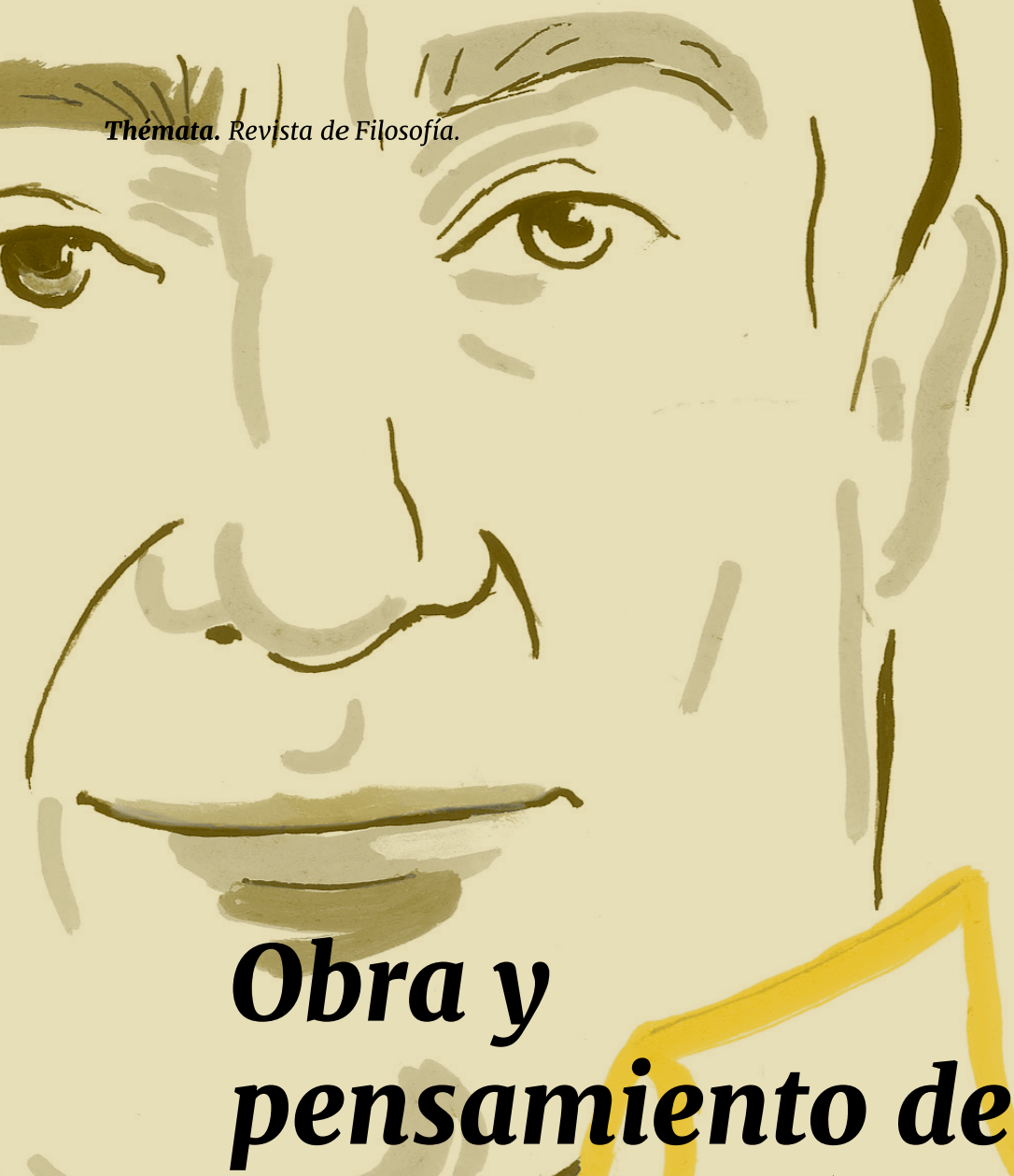

Javier HernándezPacheco Sanz. 


\title{
Un viaje de ida y vuelta: de cómo el refugio se torna apertura. El proyectar(se) como apertura a lo Otro.
}

\author{
A round trip: how the refuge becomes \\ open. Projecting (oneself) as an opening \\ to the Other.
}

\begin{abstract}
Elisa Fernández Bascones ${ }^{1}$
Universidad de Sevilla, España

Recibido 3 marzo 2021 · Aceptado 1 diciembre 2021
\end{abstract}

\section{Resumen}

Construir, habitar, proyectar. Claves para una idea romántica de arquitectura, es un pequeño pero magnífico texto del catedrático de Filosofía de la Universidad de Sevilla Javier Hernández-Pacheco que nos invita a repensar la condición espacio-existencial del ser humano. De la mano de este polifacético pensador, $\mathrm{y}$ de la de otros como Heidegger, Sloterdijk o Trías, nos atrevemos a reflexionar en torno a la estructura existencial del Dasein como equilibrio necesario entre interior y exterior, entre cobijo y apertura, entre intimidad y proyección, pero también entre pasado, presente y futuro. Para un existente que es espacial e histórico, la arquitectura como proyecto humano emerge como vehículo entre los umbrales espaciales y temporales.

Palabras clave: espacio; tiempo; interior; exterior; arquitectura; proyecto.

\section{Abstract}

Build, inhabit, project. Keys to a romantic idea of architecture, is a small but magnificent text by Javier Hernández-Pacheco, professor of Philosophy at the University of Seville, which invites us to rethink the existential-space condition of the human being. From the hand of this versatile thinker, and that of others such as Heidegger, Sloterdijk or Trías, we dare to reflect on the existential structure of Dasein as a necessary balance between interior and exterior, between shelter and openness, between intimacy and projection, but also between past, present and future. For an existence that is spatial and historical, architecture as a human project emerges as a vehicle between spatial and temporal thresholds. Keywords: space; time; interior; exterior; architecture; project. 


\section{1・ Introducción}

Basta con echar un rápido vistazo a la bibliografía de Javier Hernández-Pacheco para tomar conciencia de la amplitud y variedad de temas que logró abarcar a lo largo de su vida: teología, metafísica, filosofía de la guerra, filosofía de la economía, reflexiones sobre el amor, sobre la muerte, Ilustración y Romanticismo, etc. Desde Aristóteles hasta Heidegger, pasando por Tomás de Aquino, Hegel, Bloch, Kant, Schelling, Adorno o Apel, Hernández Pacheco no dudaba en sumergirse en la historia de la filosofía para rescatar y actualizar los pensamientos e inquietudes que acompañan al hombre desde el origen de los tiempos, todo ello con su personal estilo, riguroso pero accesible y cercano, haciendo fácil lo difícil.

Tras la tristísima noticia de su fallecimiento, revisando su obra di con un artículo que llamó poderosamente mi atención: Construir, habitar, proyectar. Claves para una idea romántica de arquitectura. Este pequeño escrito, de título en claro homenaje a Heidegger, es la transcripción de una conferencia realizada en los cursos de otoño de 2012, año de mi ingreso en la Facultad de Filosofía de la Universidad de Sevilla, en el Seminario de Filosofía Espacios Filosóficos. El lugar de la filosofía en el presente, de cuya celebración tuve noticia pero al que lamentablemente no pude asistir. Es por ello que me resultó altamente gratificante el encuentro con este texto, que tan directamente conecta con mis actuales investigaciones sobre el espacio existencial en Heidegger.

Javier Hernández-Pacheco se atrevía con todo, incluso con está magnífica reflexión en torno al espacio y a las posibilidades de la arquitectura desde una perspectiva fenomenológico-heideggeriana en la que tienen cabida pensamientos sobre el desierto y el refugio, la domus romana y los señoriales castillos, la cabaña de Heidegger y los rascacielos neoyorkinos, la torre Pelli y su querida Giralda.

El ánimo que muestra Hernández-Pacheco al aventurarse por el terreno arquitectónico evidencia la posibilidad (casi la obligación) de la filosofía de dedicarse a los asuntos de la vida cotidiana, de aquello que nos es próximo, de aquello que nos ocupa: cómo no pensar, entonces, sobre el espacio habitable y habitado, sobre la capacidad y posibilidad de construir que define al hombre desde sus orígenes. Además, la relevancia de la 
arquitectura como motivo de reflexión es puesta de manifiesto por el propio Hernández-Pacheco en su texto cuando afirma que "ser, existir, vivir, tiene para nosotros esencialmente que ver con el espacio" (2). Primero Heidegger, luego Sloterdijk, servirían de apoyo a esta propuesta sobre el espacio existencial como fondo radicalmente humano. De hecho, Sloterdijk pone de manifiesto, en su obra Esferas I, Burbujas, Microesferología, la importancia del concepto de espacio afirmando que

Pocos intérpretes de Heidegger parecen tener claro que bajo el sensacional título programático de Ser y tiempo se esconde también un tratado germinalmente revolucionario sobre ser y espacio. Bajo la impresión del encanto de la analítica existencial del tiempo heideggeriana se ha pasado por alto la mayoría de las veces el hecho de que está anclada en una correspondiente analítica del espacio, así como que ambas, a su vez, se fundan en una analítica existencial del movimiento. De ahí que sobre la doctrina de Heidegger de la temporalización e historicidad -la ontocronología- pueda leerse una biblioteca entera, sobre si teoría del movimiento y ontocinética, algunos ensayos, y sobre sus planteamientos de una disposición originaria del espacio u ontotopología -excepto paráfrasis pietistas no dignas de mención- nada. (Sloterdijk 2003 305)

Y Heidegger ya había definido el ser del propio Dasein como una suerte de esfera interna:

Dirigiéndose hacia...y aprehendiendo algo, el Dasein no sale de su esfera interna, en la que estaría primariamente encapsulado, sino que, por su modo primario de ser, ya está siempre "fuera", junto a un ente que comparece en el mundo ya descubierto cada vez. Y el determinante estar junto al ente por conocer no es algo así como un abandono de la esfera interna, sino que también en este "estar fuera", junto al objeto, el Dasein está "dentro" en un sentido que es necesario entender correctamente; él mismo es el "dentro" en cuanto es un estar-en-el-mundo-cognoscente. (Heidegger 2016a 83)

Pero esta esfera interna que es el Dasein no es comparable a una 
cápsula cerrada, puesto que el Dasein está continuamente volcado en ese dirigirse-hacia que es aprehender, un estar-(de alguna manera)-fuera. El Dasein, en este "estar en una esfera interna" pero sin embargo "salir fuera" se constituye estructuralmente como apertura.

Dicha estructura configura el mundo, de la misma manera que el mundo configura la estructura del Dasein. Esta apertura del Dasein en Heidegger es el fundamento de su propuesta del claro del bosque como lugar de encuentro entre Dasein y Ser: Heidegger entiende que el modo de ser propio del hombre, que es su ex-sistencia, es estar en el claro del ser, siendo este "claro" un símbolo, como decimos, del re-acercamiento entre el hombre y el Ser. Heidegger considera que estar en el claro del ser (que, decíamos, es la esencia-existencia del Dasein) significa ser libre en el mundo, no estar atado a un entorno (para lo que el lenguaje cobrará un papel fundamental -de ahí que Heidegger proponga a los poetas como guardianes de la morada del ser). Dice Heidegger: "si a las plantas y a los animales les falta el lenguaje es porque están siempre atados a su entorno, porque nunca se hallan libremente dispuestos en el claro del ser, el único que es mundo" (2000 31).

El término "esfera interna", utilizado por Heidegger, nos conduce de nuevo al gran pensador de las esferas: Sloterdijk dice del proyecto heideggeriano de Ser y tiempo que éste "puede entenderse también como un intento de desenterrar - al menos en un aspecto esencial- el proyecto Ser y espacio, subtemáticamente implícito en la obra temprana de Heidegger" (2003 312). Al insistir en la idea de circunmundo no como una esfera cerrada sino abierta-a, la propuesta de Sloterdijk conecta con la de Heidegger, y a su vez con la de Hernández-Pacheco, en la medida en que todos presentarían el espacio humano como una suerte de equilibrio, pues éste encontraría su esencia en un interior mediado por un exterior. Así, como ocurre con la estructura de una frágil burbuja, lo interno y lo externo parecen necesitarse para existir. El mundo exterior aparece como constitutivo del Dasein interior, y viceversa. El existente comienza en un recogimiento interior (dual, dirá Sloterdijk) para abrirse en expansión. 


\section{$2 \cdot$ Hogar y patria: construcción del espacio interior}

Así, el existente, que comienza en el cuerpo cavernoso uterino para ir trasladándose progresivamente de esfera en esfera, de caverna a cueva, de cueva a choza, cabaña, casa, edificio, castillo, palacio, etc., es, de alguna manera, el que moldea el espacio exterior: "podríamos hablar de algo así como la marsupialidad de la vida: nada más nacer todo lo vivo busca refugio saliéndose de la exterioridad, o volviendo en cuanto puede a lo que la madre aun puede ofrecer de seno, alimento y calor" (Hernández-Pacheco 3). El espacio comienza siendo, dice Hernández-Pacheco, negatividad, exposición. El existente busca la acotación espacial: ese es el origen de la arquitectura, la búsqueda de la positividad del espacio: "el valor esencial, mínimamente arquitectónico, es el aislamiento frente al medio hostil" (Ibid. 6).

Peter Sloterdijk fundamenta el "derecho espacial" (2003 252) del existente en la clausura en la madre. Para él, el tránsito del nomadismo al sedentarismo posibilita la identificación entre el mundo materno y el espacio cultivado: se torna necesaria la identificación con un suelo, con un terreno, unas posesiones, un lugar. Así, la antorcha se torna lumbre y hogar, y emerge la construcción de la casa como arquitectura originaria. El fuego emerge, como dice Sloterdijk, como primer dios, como congregación íntima. Es fundamento del hogar y del templo, y es en torno a él que se funda la patria:

Esto significa explicar de una vez por todas la extendida inclinación de los seres humanos a preferir la patria, deduciendo el efecto-patria de la sensación de bienestar en el lugar propio. Ilustración ecuménica, estilo romano. Así se vuelve reversible la conexión entre patria y sentirse-bien. Si estas en la patria, es que te va bien; si no te va bien, no estás en casa. Si la patria no procura el bene vivere, no merece su nombre; en consecuencia, se puede y se debe intentar otras posibilidades, sea como emigrante, sea como destructor de las condiciones domésticas. En un discurso del 29 de noviembre de 1792 Saint-Just explicará: un pueblo que no es feliz no tiene patria. Desde entonces, los condenados vernáculos de esta tierra están de camino en alguna 
parte donde son más felices. (...) Los seres humanos no están en casa en una tierra o en un país, sino en un confort. (Sloterdijk 2006 305)

La intimidad doméstica, el espacio hogareño, es la convivencia de seres humanos con seres humanos y de seres humanos con sus acompañantes anímicos, invisibles y originarios. La casa, como luego el reino, se convierte en interioridad que debe ser protegida. Las casas y los reinos se consolidan en un primer momento como mundos interiores. Emergen así las figuras como el genio romano o los ángeles: espíritus protectores y anímicos en torno al espacio cerrado. Entre los antiguos, dice Sloterdijk, la existencia no se concibe como vida individual sino que tiene una estructura medial: la presencia del genio corrobora que el individuo no alberga en sí su principio psíquico:

Por ello, la vida individual nunca puede representarse entre los antiguos sólo como un punto anímico aparte, como una chispa encerrada o como una llama aparte; la existencia siempre tiene ya una estructura esférica y medial, dado que el sujeto está situado en un campo semidivino de protección y atención. Todo individuo pende de un entorno espiritual, da igual que al espíritu protector se le represente como un acompañante con carácter de persona que reside en un vis-à-vis invisible, o que se le conciba auráticamente en el entorno como un medio divino que camina con el sujeto. (Sloterdijk 2003 386)

Genio, ángel de la guarda, alma exterior, emergen como concepciones elementales del "segundo polo del dúo psicoesférico" (Ibid. 396).

El acompañante originario, ese principio existencial que Sloterdijk personifica y encarna a través de diferentes figuras (la placenta, el ángel, el genio), actúa de membrana, se preocupa tanto de la formación y apertura del espacio como de su cuidado y cierre. Si se produce un desequilibrio en su función, se podrían llegar a producir, según Sloterdijk, dos opciones extremas (2003 398): por una parte, lo que llama el autismo del gemelo: si la membrana que conecta interior y exterior no es lo suficientemente porosa, el espacio entorno puede convertirse en prisión: se produce una protección espacial exagerada. Por otro lado, el miedo al exterior como espacio de aniquilación: si dicha membrana se ausenta, se pierde, el sujeto cae fuera en un éxtasis 
nocivo: se produce una protección espacial insuficiente.

La estructura existencial del sujeto, del ser humano, es una estructura de duplicidad protectora-permeable que empieza en el espacio prenatal. Vemos, por tanto, ese equilibrio entre interior y exterior necesario para el correcto desarrollo de la existencia: ni clausura, ni absoluta exposición.

Por eso, tras asegurar o garantizar ese espacio primario hogareño, en un principio cerrado, el existente, mediante la arquitectura, se expande, como dice Hernández-Pacheco, se expande hacia la luz mediante balconada $\mathrm{y}$ porche, y el bosque, antes amenazante, se convierte en parque. La arquitectura se convierte en madre del habitar transformando un espacio que originariamente es arrojo, intemperie y amenaza. Y lo hace desde el prendimiento del fuego como origen del hogar, hasta su expansión por los terrenos y sus dominios de las alturas.

\section{3- Expansión y apertura: la conquista espacial}

Aparece, en la obra de Esferas, el huevo como viejo motivo del surgimiento de la vida. La figura del huevo es útil para explicar lo que Sloterdijk llama un "doble acto" (2003397): la producción del mismo por una facultad materna y la autoliberación del ser vivo de sus cáscaras o coberturas originarias. El huevo "es símbolo de la forma que cobija y su rotura" (Id.). Existir es la "mudanza de la envoltura más estrecha a la proximidad más ancha" (2003 398), significa "venir-de-dentro". Las envolturas (membranas, gelatinosas, porosas) actúan de límite o frontera, en todos los sentidos: cierran lo interior frente a lo exterior, pero también son puerta que puede abrirse, permiten permeabilidad, son conexión. El límite ha de dejar de entenderse, como propone Eugenio Trías, el gran pensador de la frontera, como instancia negativa. Ese negativismo es el que Trías pretende superar con su filosofía de la frontera. El límite no solo escinde, sino que une, no solo es posibilidad de cierre, sino de apertura:

Por el hecho de que la puerta, por así decirlo, pone una articulación entre el espacio del hombre y todo lo que está fuera del mismo, por esto, supera la separación entre el dentro y el fuera. Precisamente porque también puede ser abierta, su 
cerrazón da la impresión de un aislamiento más fuerte frente a todo lo que está más allá de este espacio que la pared meramente divisoria. Ésta es muda, pero la pared habla. Es esencial para el hombre, en lo más profundo, el hecho de que él mismo se ponga una frontera, pero con libertad, esto es, de modo que también pueda superar nuevamente esta frontera, situarse más allá de ella. Y del mismo modo el hombre es el ser fronterizo que no tiene ninguna frontera. El cierre de su ser-en-casa por medio de la puerta significa ciertamente que separa una parcela de la unidad ininterrumpida del ser natural. Pero así como la delimitación informe se torna en una configuración, así también su delimitación encuentra su sentido y su dignidad por vez primera en aquello que la movilidad de la puerta hace perceptible: en la posibilidad de salirse a cada instante de esta delimitación hacia la libertad. (Simmel 251)

Emerge así la frontera, el límite, la puerta, como doble posibilidad: como posibilidad de aislamiento, de intimidad, de soledad, y como posibilidad de salida, de encuentro. Decía Bachelard: "¡no más fronteras!” No más, entendidas estas como límites que cierran. Entendamos el límite no ya como cerca, sino como lo que linda-con. Reclamemos nosotros la frontera de Trías, quien ya afirmó que "a la pregunta ¿Qué es el hombre? debe responderse: el habitante de la frontera" (Trías 414). Desde la perspectiva sloterdijkiana de la teoría medial de la coexistencia, lo interior precede a lo exterior. Pero, y esto resulta fundamental, lo exterior siempre llega, siempre acontece.

La propuesta de Hernández-Pacheco narra el viaje mental, existencial, filosófico, que hace el existente en un movimiento de ida y vuelta hacia un interior y un exterior, para precisamente defender esta idea de equilibrio, pero insistiendo precisamente en la capacidad proyectiva, en la posibilidad y necesidad de ser-hacia-afuera (o hacia-arriba), del existente. HernándezPacheco acierta a explicar esta originaria tendencia al exterior del Dasein recordando que

La vida es lo que originalmente se enfrenta con lo que está fuera de sí; ella misma está fuera de sí. Lo podemos decir de muchas maneras: en esa original dimensión ex-sistencial, la vida es lo ex-puesto, lo derelicto, das Geworfene, lo arrojado fuera. (2) 


\section{4・Aspiración monumental como elevación existencial}

Es inevitable pensar, a partir de esta defensa que Hernández-Pacheco lleva a cabo de la monumentalidad arquitectónica, de la crítica heideggeriana a la modernidad: modernidad entendida no ya, o no sólo, recordemos, como época comprendida entre los siglos XV y XIX, sino como un modo de representarse el mundo. Para comprender la contraposición que propongo entre la visión arquitectónica de Hernández-Pacheco y la de Heidegger, resulta fundamental la definición de útil que éste lleva a cabo, y que distingue de cosa y de objeto. En el planteamiento que Heidegger hace en Ser y Tiempo emergen los útiles o utensilios como aquello de lo que nos hacemos cargo en nuestro espacio familiar y habitable, en nuestro circunmundo. El alemán define el modo de ser de los utensilios como el estar-a-la-mano: comprendemos lo que son los utensilios precisamente utilizándolos. Así, podríamos distinguir entre las cosas, que están ahí, en su mera presencia, y los utensilios, que se caracterizan por el estar-a-la-mano, por su uso. Lo que hace a una cosa ser más ella misma es convertirse en útil, usarla, vivirla. El mundo se forja usando(lo). Esto puede observarse con bastante claridad en el famoso fragmento de Heidegger sobre las botas de campesino:

Tomaremos como ejemplo un utensilio corriente: un par de botas de campesino. Para describirlas ni siquiera necesitamos tener delante un ejemplar de ese tipo de útil. Todo el mundo sabe cómo son (...) Pero ¿qué decir de ésta? ¿Capta ya la utilidad el carácter de utensilio del utensilio? Para que esto ocurra ¿acaso no tenemos que detenernos a considerar el utensilio dotado de utilidad en el momento en que está siendo usado para algo? Pues bien, las botas campesinas las lleva la labradora cuando trabaja en el campo y sólo en ese momento son precisamente lo que son. Lo son tanto más cuanto menos piensa la labradora en sus botas durante su trabajo, cuando ni siquiera las mira ni las siente. La labradora se sostiene sobre sus botas y anda con ellas. Así es como dichas botas sirven realmente para algo. Es en este proceso de utilización del utensilio cuando debemos toparnos 
verdaderamente con el carácter de utensilio. Por el contrario, mientras sólo nos representemos un par de botas en general, mientras nos limitemos a ver en el cuadro un simple par de zapatos vacíos y no utilizados, nunca llegaremos a saber lo que es de verdad el ser-utensilio del utensilio. (Heidegger 2016b 49)

Las cosas se hacen usándolas: coge las botas y póntelas. Podemos aportar ahora una distinción más, además de la ya expuesta entre cosa y útil: el objeto. El objeto sería la cosa o el útil objetivizado, despojado de un mundo originario, incrustado en un mundo desencantado. Se podría decir, por tanto, que manejamos tres conceptos o niveles de mundo:

1. El mundo de la cosa originaria. La modernidad, según Heidegger, despoja a las cosas de mundo, de arraigo y de despliegue (y las convierte en objetos). Desde este punto de vista, la lechuga del huerto posee más mundo (originario) que la del supermercado.

2. Por otro lado, el mundo del útil: este mundo se forja usando las cosas, pero no en un sentido pragmático o utilitario sino dándoles uso, dándoles vida, en el sentido antes comentado.

3. El mundo moderno: para Heidegger, el mundo moderno limita, acota, humilla y olvida. ¿Qué olvida el mundo moderno? Precisamente el fondo originario que Heidegger reconoce tan solo en la rusticidad.

Pongamos un ejemplo, aterrizando de nuevo en el mundo de la arquitectura como modificación espacial: la contraposición entre choza y palacio, o la contraposición entre camino de cabras y autopista. Cada par de las realidades sugeridas encarna un fondo originario: en el primer caso, el fondo originario del habitar; en el segundo, el fondo originario del caminar. Todos ellos son acotaciones del espacio y del camino, o del habitar y el caminar. El mundo moderno se forja poniendo límites: donde solo había campo, ahora hay parque. Donde solo había terreno, ahora hay camino, ahora autopista. Donde solo había desierto, ahora hay choza, ahora palacio.

Pero, además, diría Heidegger, el mundo moderno humilla, en la medida en que valoraría más el palacio y la autopista que la choza y el camino de cabras, olvidando sus respectivos fondos originarios, que son el mismo. Desde esta perspectiva, la choza y el camino de cabras, en su rusticidad, estarían más cerca de la verdad del habitar y del caminar. La verdad del 
palacio y de la choza es la misma, pero el palacio corre el riesgo de olvidar más fácilmente su fondo originario, que al final es el mismo que el de la choza.

Con la magnífica aportación que hace Hernández-Pacheco en el texto que estamos comentado, pone de manifiesto que no comulga con esta visión, con esta crítica al mundo moderno tan propiamente heideggeriana. Por el contrario, para Hernández Pacheco, choza y camino serían el origen de un largo viaje proyectivo propio y característico de un existente que primero habita un interior, un hogar, y después se expande hacia lo que está más allá, llegando a concebir y construir el palacio y la autopista. La virtud humana de proyectar es el origen de la catedral gótica, del rascacielos, del palacio, de la autopista. Así, la arquitectura es "una forma de vivir, de apropiarse del espacio privado y, por extensión, del espacio público" (Ábalos 9). Aldo Hidalgo expresa esta idea de apertura o ampliación del espacio interior a través, precisamente, del caso de la cabaña de Heidegger como motivo fundamental del espacio interior o espacio íntimo:

Cuando Heidegger deja la interioridad de la cabaña se mueve por senderos y claros de luz entre la masa boscosa, y se encuentra con las aberturas que dejan entre ellas las cabañas cercanas, con los intersticios y senderos entre colina y colina. Heidegger en sus paseos reflexiona: "Este es mi mundo de trabajo [...] Hablando con rigor, nunca contemplo el paisaje” (Heidegger, "Construir, habitar, pensar" 116). Los senderos de travesía, paseos y de esquí que conducen o alejan la cabaña, su lugar, espacian el espacio. Y solo por la relación con la interioridad de la cabaña se constituye lo abierto. El sendero provee la libertad de movimiento para la constitución del espacio mismo, así como vimos el rol que juega el espacio al modo de los cuartos ensamblados para desplegar una totalidad. Por medio de sus paseos aparecen lugares de encuentro desde los cuales se miden existencialmente distancias, direcciones y traspasos: "Y solo porque los mortales, conforme a su esencia, aguantan espacios pueden atravesar espacios" (Heidegger, "Construir, habitar, pensar" 116). El desplazamiento por el bosque despeja, libera para hacer espacio. Y en este hacer espacio, el espacio espacia (der Raum räumt), ello proviene del 
carácter puntual y unitivo de la cabaña en tanto lugar (Ort) y el acto de moverse hacia fuera del recinto íntimo y la extensión hacia la comarca (Gegend). En el hecho de recorrer y estar orientado hacia la exterioridad misma es donde el espacio acontece. Este movimiento por caminos o sendas no solo define el ritmo de las acciones complementarias con aquellas del interior de la cabaña, propias de la cotidianeidad, sino que en virtud de la experiencia de recorrer el espacio (spaziergang), se espacia el espacio. (Hidalgo)

Desde el interior de la cabaña, del espacio hogareño, salimos hacia afuera, por los caminos, a la amplitud de la comarca, en el acontecimiento existencial-espacial por excelencia. En esta apropiación del espacio exterior, el proyectar emerge como el construir no solo en torno a lo íntimo, sino también a lo grande, y es en este sentido que contraponemos la propuesta de Hernández-Pacheco a la propuesta heideggeriana. Contra Heidegger y su defensa de (cierto sentido de) la rusticidad, Hernández-Pacheco se reafirma en su posición y confiesa que a él le "gustan los rascacielos, los proyectos faraónicos, las obras públicas" (15). Le gustaba, por supuesto, la catedral de su ciudad adoptiva que acoge a esa Giralda querida. La catedral de Sevilla, en su goticismo, es un claro ejemplo de expansión y proyección arquitectónica ya no solo hacia afuera, sino hacia arriba. Wilhelm Worringer dice de la catedral gótica que en ella

Veremos, por decirlo así, un movimiento vertical petrificado, en el cual la ley de la gravedad parece anulada. Veremos un movimiento de inaudita fuerza, dirigido hacia arriba, opuesto a la natural dirección de la gravedad pétrea. No hay muros, no hay masas que nos den la impresión de realidad firme y material. Mil fuerzas nos hablan, sin dejar que nos demos cuenta de su materialidad, actuando como heraldos de una expresión inmaterial, de un movimiento irreprimido de ascensión. (84)

La arquitectura gótica ya no busca, sobre todo, la protección, el cobijo, la fortaleza en torno a un interior, sino que en su expresión artística pretende el ascenso, la subida, la elevación de lo material como símbolo de elevación espiritual. El alma gótica, 
torturada por la realidad, excluída de la naturaleza aspira a un mundo suprarreal, suprasensible. Necesita sentir el vértigo para erguirse sobre sí misma. Solo en la embriaguez percibe el estremecimiento de la eternidad. Este histerismo sublime es el que, principalmente, caracteriza el fenómeno gótico. (Worringer 65)

Quizá la confesión y la defensa que lleva a cabo Hernández-Pacheco de lo monumental arquitectónico como expresión existencial solo pueda hacerse desde el punto de vista, como Hernández-Pacheco diría, de un cateto en la ciudad: es decir, precisamente desde la visión de quien viene de lo rústico y reconoce y sabe del deseo y el esfuerzo de proyección, de ascenso, de mejora y aspiración hacia un lugar mejor. Así, en contra de la (ciertamente algo manida) visión pecaminosa del ladrillo, de la maldición que cayó sobre los altos edificios, vistos como intentos de superar a Dios ya desde los orígenes de nuestra historia, Hernández-Pacheco defiende la arquitectura "como el proyecto siempre inacabable de una vida mejor" (Id.). Destaca así el ladrillo como humilde origen de la proyección arquitectónica:

Un ladrillo me parece, en su solidez, en su fácil manejo (es un espectáculo ver como el peón los va echando, uno tras otro, al oficial hasta lo alto del andamio), en su versatilidad (piénsese de cuántas formas se puede poner para hacer un muro, de un pie, de medio, tabique, panderete, tabiquillo, etc), uno de los productos más humildes, pero más milenarios y nobles, del ingenio humano (...) Pero efectivamente no podemos olvidar que, en su aparente solidez, son de barro, tan precarios como la existencia ala que pretenden dar albergue. Y entonces sí me atrevo a una última palabra: la arquitectura, y con ella el afán constructivo de la historia humana, no puede olvidar de dónde vienen, sobre qué cimiento se asientan, que no es otro que la radical finitud. Y por eso todo edificio está destinado a derrumbarse. (16)

Hacia afuera, y hacia arriba: desde el interior del hogar, una vez asentado el fuego, el existente construye, proyecta. En un gesto de ida y vuelta, el existente, ese que no tiene más remedio que refugiarse desde su abandono de la esfera primigenia, ese que trata de construir y reconstruir 
ese habitáculo protector, vuelve a sus afueras. Y entonces, la clausura en la madre de la que hablaba Sloterdijk, el seno materno, se convierte no solo en punto de partida sino en lugar al que volver porque, en efecto, ha habido que salir-allí-afuera a encontrarse con lo Otro. La arquitectura emerge como encarnación de la forma existencial humana, cobijo y expansión, protección y promesa de creación de aquello que todavía no existe.

\section{$5 \cdot$ La arquitectura como búsqueda de equilibrio en el tiempo}

Hacia aquello que todavía no existe, decíamos, como proyecto de futuro, y hacia aquello que existió, podemos decir ahora, como memoria del pasado. El poder de la arquitectura se manifiesta no solo a través de la proyección espacial, sino también a través de la proyección temporal. La arquitectura surge como origen del primer recinto íntimo, muralla del hogar primigenio, viaje hacia un interior y un anterior, como despliegue hacia el exterior, hacia afuera y hacia arriba, hacia el futuro como esperanza, y como despliegue hacia un pasado como memoria.

Veamos ahora, a través de las obras de distintos arquitectos, cómo el arte de la memoria subyace bajo la arquitectura contemporánea. Gabriel Bascones de la Cruz pone de manifiesto el evidente vínculo entre arquitectura y memoria, entre arquitectura y pasado resaltando

el sentido y destino de las ruinas, el poder evocador de los fragmentos, la pertinencia de la deslocalización de los mismos, las fórmulas de construcción de la identidad en una ciudad refundada, el paisaje y territorio como elementos identitarios, la validez o no de incorporación de nuevos usos en los elementos patrimoniales, la memoria colectiva frente a la individual, etc.

(Bascones 24)

La arquitectura, como vamos a ver a continuación, surge como protección del pasado y como proyección de futuro. Por tanto, nos encontramos ante un despliegue espacial, hacia un interior y hacia un exterior, sobre el que ya hemos hablado, y ante un despliegue temporal.

Resulta sumamente interesante detenerse en un ejemplo de lo que 
Gabriel Bascones propone, en su obra Francesco Venezia y John Hejduk: La vigencia del arte de la memoria en la arquitectura contemporánea ${ }^{2}$ como arquitectura de la memoria. El 15 de enero de 1968 Sicilia fue asolada por un duro terremoto que destruyó, entre otras, la ciudad de Gibellina. Como parte del proyecto de construcción de la nueva ciudad, que decidió construirse a 18 $\mathrm{km}$ de las ruinas de la original, Ludovico Corrao, alcalde de Gibellina durante el fatídico acontecimiento, propuso que el fragmento de fachada del Palacio Di Lorenzo, superviviente al envite, fuese trasladado al nuevo municipio incorporándolo a un edificio de nueva creación y se convirtiese así, de alguna forma, en puerta de entrada a la nueva Gibellina. Este proyecto fue encomendado a Francesco Venezia. La arquitectura emerge en este proyecto como soporte de la memoria (Bascones 37). Para Venezia, intervenir allí significa trabajar

\section{Para una comunidad a la que urge la restauración del equilibrio interrumpido, la armonía con su entorno, reactivando ampliamente las relaciones con la naturaleza, he querido que el museo del palacio de Lorenzo, apropiado porque acoge en la Gibellina nueva el testimonio de la Gibellina destruida, fuese una "máquina óptica para disfrutar del paisaje. (Venezia 81)}

Como dice Gabriel Bascones respecto al proyecto de Venezia, este "crea un lugar de evocación que reclama la permanencia del recuerdo de la ciudad abandonada" (63). Vemos como la arquitectura emerge como vehículo al pasado, como vínculo entre pasado y presente, como esperanza de reconstrucción, como promesa de futuro, de despliegue, pero de un despliegue que no olvida sus raíces.

Otro de los proyectos que Gabriel Bascones trabaja en su obra es el Cretto de Gibelina, llevada a cabo por Alberto Burri. Tomo su palabra para describir en qué consistían los cretti, las obras en las que está basado este proyecto:

Consistían en la realización de un emplaste de creta, blanco de zinc o caolín y colas mezcladas con arena o tierra, que el 
artista extendía en tablas de madera. Estas eran sometidas a un meticuloso proceso de secado, que con la evaporación del agua provocaban el agrietamiento y la fragmentación de la masa, como las arcillas naturales en procesos de sequía. En este proceso había perdido papel activo el autor, pues se trataba de una transformación de la materia al someterla a un fuerte cambio de estado, en el que el artista controlaba las condiciones del proceso, pero no el resultado final. La esencialidad del único material utilizado y de lo natural del proceso, conseguían una gran fuerza estética a la que se suma la expresividad del efecto del tiempo. La obra de arte surge como el estado final de un proceso de transformación de la materia. (Bascones 109, 111)

El proyecto del Cretto en Gibelina consistió, por tanto, en aplicar esta técnica sobre las ruinas de la ciudad, convirtiendo las manzanas de la misma en enormes bloques blancos conectados por las antiguas vías, de manera que los antiguos habitantes pudieran revivir sus vivencias recorriendo las calles así conservadas. Como dice Gabriel Bascones, la principal aportación del proyecto de Burri fue

entender que, a pesar de estar conviviendo con una realidad dramática, de verdadera emergencia social, la identidad de la nueva ciudad pasaba por cuidar la cultura. La cultura y el arte eran necesarios para generar ciudad desde sus inicios, cuando ocuparan los habitantes de Gibellina sus nuevos hogares tras los trece años de vida en barracas temporales. (111,113)

C. Díaz y E. García reconocen el valor de la obra de Burri afirmando que

El Cretto es un instrumento de negociación con el lugar y la memoria proporcionado por Burri a una población enajenada y desarraigada que, a través de la identificación de la forma de un proceso de reestructuración de la materia -cercano en algunos aspectos al que sufrió Gibellina- y aquella de la población destruida, se convierte en un mecanismo que liga acontecimientos, configuración y tiempo. (83)

Para ellos, 
El Cretto no pretenderá combatir el olvido acumulando memoria, mediante una operación nostálgica que desafíe el paso del tiempo, que evoque y perpetúe imágenes recuperables, sino más bien construir otra ciudad opuesta a la nueva Gibellina, que condense su identidad y permita a sus habitantes una relación no traumática con su pasado; capaz de, manipulando el tiempo, dotar a la memoria y al lugar de una imagen abstracta, no alusiva, y crear en ella un paisaje artificial de máxima intensidad en este paraje desolado del interior de Sicilia. (82)

Este proyecto arquitectónico permite, como vemos, una suerte de reconciliación con el pasado que permita una posibilidad esperanzadora de futuro. Sin embargo, no faltan detractores al proyecto de Burri. Además de Benedetta Rodegiero, que lo rebate "por negar cualquier posibilidad de establecer una correspondencia con el objeto original" (205), Francesco Venezia también le dedica una crítica desde su defensa de una idea de arquitectura que tiende puentes hacia el futuro sin congelar el pasado, como ocurriría, desde su punto de vista, con el Cretto de Burri.

Podríamos decir que Venezia se reconcilia con el el proyecto de la restauración o reconstrucción de la vieja Gibelina por parte de Burri a través de un nuevo proyecto. El arquitecto puso en marcha, gracias a Corrao, el proyecto de un teatro al aire libre en las ruinas de la ciudad. Se iniciaron así las Orestíadas, una serie de funciones teatrales estivales que utilizaron como fondo el Cretto de Burri:

Por una vez se posibilitaba un acercamiento a los restos de la ciudad con una mirada nueva, regeneradora. El efecto catártico del teatro permitió transformar la visión nostálgica y pasiva del cementerio en que se había convertido la ciudad vieja, para pasar a ser de nuevo soporte de vida, aunque solo fuese de forma temporal (...) Frente al Goliat, el monumento inerte que congelaba el proceso vital de la ciudad en ruina, esta experiencia de catarsis colectiva, llevada a cabo con acciones de poca impronta material, pero de la forma más vital, expresiva y participativa, permite todavía seguir escribiendo nuevos pasajes en la historia de la vieja Gibellina, que vuelve a ser aprehensible para sus antiguos moradores. (Bascones 117-118) 
Más allá de las diferentes interpretaciones sobre los mismos, vemos como la arquitectura emerge finalmente, en estos proyectos, como emblema de la condición humana, una condición fronteriza, limítrofe y proyectiva no solo en el espacio, como ya anunciaba Hernández Pacheco, sino también en el tiempo. Como hijos de Jano, dios de las puertas, de los umbrales, de las transiciones: dios de las dos caras, que mira hacia adentro y hacia afuera, hacia el pasado y hacia el futuro; como sus hijos, decíamos, los existentes nos erguimos como seres estructuralmente fronterizos, siempre de paso por un mundo al que llegamos y del que, irremediablemente y desde nuestra finitud, nos iremos, pero al que pertenecemos por un tiempo-compartido-con-otros y durante el cual, de alguna manera, se forjan las condiciones de nuestra fundición eterna en la memoria colectiva.

En este sentido nos cabe solo mencionar (por falta de, precisamente, tiempo y espacio) la obra de John Hejduk, que Gabriel Bascones también trabaja en su tesis y que constituye otro ejemplo de vínculo entre arquitectura y memoria o de cómo la arquitectura puede, en ocasiones, denunciar y conjurar el pasado para sanar el futuro. El trabajo de Hejduk, dice Bascones, como el de Venezia,

tiene su origen en una reclamación de la memoria colectiva por parte del arquitecto. Una reacción frente a una sociedad que, confiada en una idea de progreso, huye hacia adelante y silencia aquellos episodios del pasado doloroso. Hay en sus propuestas una actitud de lucha contra una aceptada amnesia colectiva, para reclamar la memoria del pasado, cuya aceptación y asimilación consideran necesaria para mirar hacia adelante. (188)

Los proyectos de ambos arquitectos surgen a raíz de acontecimientos traumáticos, que en el caso de Venezia es una catástrofe natural (el terremoto) y en el caso de Hejduk es un conjunto de acciones humanas: su proyecto es un singular memorial de guerra, una denuncia a la barbarie cometida en Berlín, paradigma de los crímenes cometidos contra la humanidad (Bascones 181). Este proyecto supuso la transformación de un solar próximo a la Postdamer Platz en un parque urbano. El solar estaba situado en un área desdibujada tras los bombardeos de la $2^{\mathrm{a}}$ Guerra Mundial, en el entorno del muro, y había contenido anteriormente cámaras de tortura durante la Segunda Guerra Mundial. Como decía, la complejidad del proyecto de Hejduk, que Gabriel 
Bascones describe, analiza y alberga en su tesis, hace imposible que sea aquí recogida. A modo de resumen, diremos que supone un intento de mantener vivo el pasado a través de la instalación de una troupe, de una serie de abstractos personajes que habitarán de nuevo el dramático solar y que tienen una historia que contar(nos).

Con su lucha contra el olvido, además de honrar la memoria, el vínculo con un pasado que no ha de ser negado, Hejduk nos recuerda nuestro paso por un mismo suelo, ese mismo desde dónde erigimos nuestros hogares, nuestros, templos, nuestros teatros. Nuestra proyección-hacia-afuera, esa de la que hablaba Hernández-Pacheco y que nos constituye existencialmente, implica una proyección-hacia-el-Otro con quien compartimos suelo, raíces, polvo al que nos vamos uniendo formando parte de esa tierra nutricia que da asiento y aliento a los venideros:

porque cuando inspiro, el aire que entra en mis pulmones contiene todos los sonidos de voces desde el principio de los tiempos. Todas las voces que han depositado su pensamiento en el aire. Es decir, pensamientos escapando del alma a través de la voz y hacia el aire que respiro. Sonidos que no puedo oír. Sonidos silenciosos que llenan el aire, en el que han hablado todas esas generaciones, llenándome así de mundos que son un texto invisible y sonoro que se mezcla con mis pensamientos, que son invisibles. Lo que esencialmente es una comunión interna, anunciando lo sublime de las trasferencias silenciosas. (Hedjuk, citado en Nadal 39)

\section{$6 \cdot$ Bibliografía}

Ábalos, I. La buena vida, Barcelona: Editorial Gustavo Gili S.L., 2014.

Bachelard, G. La poética del espacio, Madrid: Fondo de cultura económica, 1965.

Bascones de la Cruz, Gabriel. Francesco Venezia y John Hejduk: La vigencia del arte de la memoria en la arquitectura contemporánea. Directores: Dr. Pablo Diáñez Rubio y Dra. Esther Mayoral Campa. Departamento de Proyectos Arquitectónicos. E.T.S. Arquitectura de Sevilla, 2018. 
Díaz Moreno, Cristina y García Guinda, Efrén. "La lava blanca. El Cretto de Gibellina de Alberto Burri", en Iñaki Ábalos (Dir.): Campos de Batalla. Barcelona: Collegi d'Arquitectes de Catanunya, 2005.

Heidegger, Martin. Carta sobre el humanismo, Madrid: Alianza editorial, 2000. Heidegger, Martin. Ser y tiempo, Madrid: Trotta, 2016a.

Heidegger Martin. El origen de la obra de arte, Madrid: La Oficina Ediciones, 2016b.

Hernández-Pacheco Sanz, Javier, "Construir, habitar, proyectar. Claves para una idea romántica de arquitectura", Fedro. Revista de Estética y Teoría de las Artes 13 (2014): 1-15.

Hidalgo Hermosilla, Aldo. "Los lugares espacian el espacio", Aisthesis 54 (2013).

http://dx.doi.org/10.4067/So718-71812013000200003

Nadal, Sara: "Los lugares de la memoria. Si John Ruskin paseara por el Bronx", en Flores, Ricardo; Eva Prats, Eva (Ed.): John Hejduk. House of a Poet. Barcelona, Ediciones UP, 2000.

Rodeghiero, Benedetta. Permanenza e trasformazione in architettura. Gibellina e Salemi: cittá usate. Tesis doctoral. Director: Josep Muntañola Thornberg. Dpto. Proyectos Arquitectónicos Universidad Politécnica de Cataluña.

Simmel, George. Puente y puerta: El individuo y la libertad. Barcelona: Ensayos de crítica de la cultura, Ediciones península, 1998.

Sloterdijk, Peter. Esferas I, Burbujas, Microesferología, Madrid: Ediciones Siruela, 2003.

Sloterdijk, Peter. Esferas III, Espumas, Esferología plural. Madrid: Ediciones Siruela, 2006.

Trías, Eugenio. La razón fronteriza, Barcelona: Ediciones Destino, 1999.

Venezia, Francesco. “¿Por qué construir en Gibellina?” en Messina, Bruno (Ed.): Francesco Venezia. Architetture in Sicilia, 1980-1993 [catálogo de exposición]. Nápoles: Clean (1993).

Worringer, Wilhlem. La esencia del estilo gótico, Buenos Aires: Nueva visión, 1957. 


\section{Thémata. \\ Revista de Filosofía}

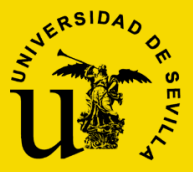

